\title{
Neuronal Circuitry and Discharge Patterns Controlling Eye Movements in the Pigeon
}

\author{
Yang Yang, Yan Yang, and Shu-Rong Wang \\ Laboratory for Visual Information Processing, State Key Laboratory of Brain and Cognitive Sciences, Institute of Biophysics, Chinese Academy of Sciences, \\ Beijing 100101, China
}

\begin{abstract}
Horizontal eye movements in humans and other vertebrates are actuated by the lateral and medial rectus muscles that are innervated by the abducens and oculomotor nuclei. Here we show by single-cell recording in the pigeon that there exist three types of abducens neurons in terms of discharge patterns, which generate the shift and/or oscillation components of a horizontal saccadic eye movement. Shiftrelated neurons discharged sustained firing around saccadic shift, oscillation-related neurons produced several bursts accompanying saccadic oscillations, and saccade-related neurons discharged both sustained firing and several bursts perisaccadically. Oscillation- and saccade-related neurons were each divided into two groups according to their firing behaviors during nasotemporal saccades: bursting activity began before (leading) or after (lagging) the onset of saccades. Abducens neurons in the lagging group but not those in the leading group were activated by antidromic stimulation of the contralateral oculomotor nucleus. Blockade of the nucleus lentiformis mesencephali and the nucleus of the basal optic root, both of which are involved in optokinetic nystagmus, abolished sustained firing in abducens neurons and shift component of saccades, whereas blockade of the saccade-related raphe complex eliminated bursting activity in abducens neurons and oscillation component of saccades. The present study revealed oculomotor circuitry in the pigeon, in which the optokinetic nuclei and the raphe complex send differential signals to abducens neurons to generate three types of discharge patterns, and thereby initiate the shift and oscillation components of a horizontal saccade.
\end{abstract}

Key words: abducens nucleus; brainstem raphe complex; extracellular recording; eye movement; oculomotor circuitry; pigeon

\section{Introduction}

Humans and other foveate vertebrates make a rapid eye movement (saccade) frequently to search for or fixate a target of interest with the fovea. When a large-field stimulus is moving, the eyes would reflexly produce optokinetic nystagmus (OKN), during which slow following and rapid resetting responses alternate for stabilizing retinal images. All eye movements are actuated by three pairs of agonist/antagonist extraocular muscles that are innervated by motoneurons in the abducens, oculomotor, and trochlear nuclei (Evinger, 1988; Büttner-Ennever, 2005). In particular, horizontal eye movements are mainly actuated by the lateral and medial rectus muscles, which are innervated by motoneurons in the abducens nucleus and the contralateral oculomotor nucleus. These neurons in mammals discharge in a phasictonic pattern around the saccade (Fuchs and Luschei, 1970; Robinson, 1970; Schiller, 1970; Delgado-Garcia et al., 1986; Stahl and Simpson, 1995). The phasic and tonic signals originate from several midbrain and brainstem structures including the paramedian pontine reticular formation (Fuchs et al., 1985; Fukushima

\footnotetext{
Received June 2, 2008; revised Aug. 18, 2008; accepted Sept. 14, 2008.

This work was supported by the National Natural Science Foundation of China Grant 90208008 and by Chinese Academy of Sciences Grant KSCX1-YW-R-32.

Correspondence should be addressed to Shu-Rong Wang, Laboratory for Visual Information Processing, Institute of Biophysics, Chinese Academy of Sciences, 15 Datun Road, Beijing 100101, People's Republic of China. E-mail: wangsr@ibp.ac.cn.

DOI:10.1523/JNEUROSCI.2468-08.2008

Copyright $\odot 2008$ Society for Neuroscience $\quad$ 0270-6474/08/2810772-09\$15.00/0
}

et al., 1992; Moschovakis et al., 1996; Moschovakis, 1997; Sparks, 2002).

However, the discharge patterns and signal origins of ocular motoneurons in nonmammals are largely unknown. In this respect, the oculomotor system in birds may provide a good model to explore these problems (Yang et al., 2008) because avian saccade consists of a shift of eye position and several cycles of oscillation (Wallman et al., 1994; Niu et al., 2006; Yang et al., 2008), and these saccadic components may originate from different neural structures. Recent studies found two types of omnipause neurons in the brainstem raphe complex, which project to the nucleus of the basal optic root (nBOR) (Toledo et al., 1995; Yang et al., 2008) and the nucleus lentiformis mesencephali (nLM) (Yang et al., 2008). Together with the fact that the raphe complex receives afferents from the optic tectum (Hunt and Künzle, 1976; Reiner and Karten, 1982; Luksch, 2003), it suggests that the raphe complex may be involved in generating saccades. However, nLM and nBOR are comparable with the nucleus of the optic tract and the terminal nuclei of the accessory optic tract in mammals, respectively (Fite et al., 1979; McKenna and Wallman, 1985) and they are involved in generating OKN (Gioanni et al., 1983a,b; WolfOberhollenzer and Kirschfeld, 1994; Fu et al., 1998; Zhang et al., 1999). These neural structures project directly or indirectly to ocular motoneurons innervating extraocular muscles (Brecha and Karten, 1979; Büttner-Ennever and Horn, 1997), suggesting that the optokinetic nuclei and the raphe complex may 

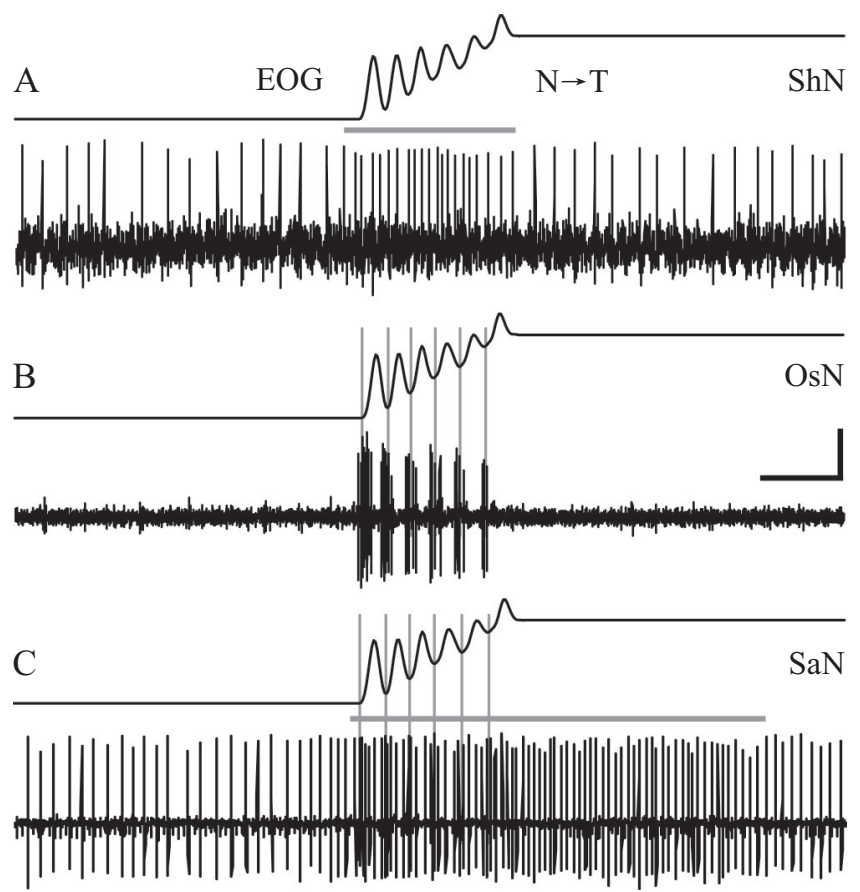

Figure 1. Recording traces show discharge pattern of each type of abducens neurons around a saccadic eye movement. $A$, Neuron was spontaneously active and discharged sustained firing during saccadic shift and thus was named an ShN. $\boldsymbol{B}$, An oscillation-related OsN had no spontaneous activity but fired several bursts corresponding to saccadic oscillations. $C$, An SaN fired several bursts and sustained discharge that lasted for awhile after the saccade end. The pigeon viewed stationary gratings and $\mathrm{N}$ - $\mathrm{T}$ saccades were made spontaneously. The duration of sustained firing is marked by horizontal bars. Vertical gray lines indicate the onset of oscillations for an individual saccade. Calibration: $2^{\circ}$ for EOG; $\boldsymbol{A}, 15 \mu \mathrm{V} ; \boldsymbol{B}, 30 \mu \mathrm{V} ; \boldsymbol{C}, 50 \mu \mathrm{V} ; 125 \mathrm{~ms}$.

play differential roles in determining the discharge patterns of ocular motoneurons and saccadic components.

To examine this suggestion, the present study was undertaken on the pigeon by using multidisciplinary techniques in three steps. First, we recorded firing activity of abducens neurons perisaccadically to find out their discharge patterns and time courses. Second, we examined effects of inactivating $\mathrm{nBOR} / \mathrm{nLM}$ or the raphe complex on firing activity in abducens neurons and eye movements. Third, we identified internuclear abducens neurons by electrical stimulation of the oculomotor nucleus.

\section{Materials and Methods}

Surgery and setup. The experiments were performed on 70 adult pigeons (Columba livia) of either sex, 300-480 g body weight, complied with the guidelines regarding the care and use of experimental animals established by the Society for Neuroscience, and approved by the Institutional Animal Administration Committee. They were divided into three groups for experimentation. The first group included 41 pigeons, each of which was anesthetized by injection of a mixture of ketamine $(40 \mathrm{mg} / \mathrm{Kg})$ and xylazine $(5 \mathrm{mg} / \mathrm{Kg})$ into pectoral muscles (Wang et al., 1995; Yang et al., 2008), and the depth of anesthesia was monitored by breathing patterns and by the reflex from pinching the toe. The pigeon was then placed in a stereotaxic apparatus and its scalp was incised and retracted, and the caudal tectum and cerebellum were exposed with a dental drill and surgical forceps. A lightweight steel headpiece connected to a steel rod was cemented onto the skull to replace the ear bars as a means to fix the pigeon's head. After the surgical opening in the scalp was closed and treated with erythromycin ointment, the pigeon was given ibuprofen as an analgesic (20 $\mathrm{mg} / \mathrm{kg}$ ) for postoperative pain and returned to its home cage for recovery from anesthesia. Within $8-12 \mathrm{~h}$, the pigeon's standing, walk- ing, and pecking behaviors had returned to normal. It then was lightly anesthetized with ketamine and xylazine and wrapped in a bag and placed on a foam couch in the stereotaxic apparatus. Its headpiece was reconnected to the rod for stereotaxic fixation, and the wound edge and muscles were infiltrated periodically with lidocaine (Yang et al., 2008). The dura mater overlying the right abducens nucleus and that overlying the left oculomotor nucleus were excised and the brain surface covered with liquid paraffin. The pigeon's adaptation to the restraint was signaled by the observation that it sat unruffled in the apparatus within $2 \mathrm{~h}$, both single cell activity of abducens neurons and electrooculogram (EOG) of the right eye were then simultaneously recorded. In addition, some of the abducens cells were examined for responses to antidromic stimulation of the left oculomotor nucleus for identifying internuclear neurons. The second group of 19 pigeons was prepared as the first group except that a small part of the rostral tectum, caudal forebrain, and cerebellum on the left side were exposed for examining the effects of reversible blockade of the optokinetic nuclei $\mathrm{nBOR} / \mathrm{nLM}$ or the raphe complex by GABA on firing activity of abducens neurons. Meanwhile, changes in EOG signals during blockade of these structures were also examined. The third group of 10 pigeons was prepared as the second group, but the optokinetic nuclei or the raphe complex was electrolytically or chemically lesioned and EOG signals were then examined after $5 \mathrm{~d}$ of survival. Meanwhile, changes in firing activity of abducens cells were also examined in these pigeons.

The right eye of the pigeon was held open during recordings, and otherwise its lids were allowed to move freely. The left eye was covered. A tangent screen of $130^{\circ}$ vertical by $140^{\circ}$ horizontal was placed $40 \mathrm{~cm}$ away from the viewing eye. The horizontal axis of the visual field on the screen was rotated by $38^{\circ}$ to match the pigeon's normal conditions (Cao et al., 2004; Niu et al., 2006; Li et al., 2007; Yang et al., 2008).

Visual stimuli. A whole-field square wave grating consisting of equal-width black and white stripes with a spatial frequency of 0.25 cycles/degree was generated by a computer with graphics (GeForce 7950 GT; Nvidia; maximum refresh rate, $400 \mathrm{~Hz}$ ) and rear-projected onto the screen by a projector (XG-C58X; Sharp; maximum refresh rate, $200 \mathrm{~Hz}$ ). The luminance of black and white in the visual stimulus was 0.1 and $6.6 \mathrm{~cd} / \mathrm{m}^{2}$, respectively. The grating stayed stationary on the screen for $60 \mathrm{~s}$ for recording neuronal activity as controls during spontaneous saccades. It was then moved at $2-128 \% \mathrm{~s}$ for $60-100 \mathrm{~s}$ in the temporonasal $(\mathrm{T}-\mathrm{N})$ and nasotemporal $(\mathrm{N}-\mathrm{T})$ directions to elicit OKN (Gioanni et al., 1983). The interval between consecutive trials was $20 \mathrm{~s}$ to allow neural responses to recover fully from any adaptation.

Electrodes and recording. Four types of electrode were used. (1) A glass-coated tungsten microelectrode was used for single-cell recording and electrolytic marking of recording sites (Donaldson and Knox, 1991). Action potentials were amplified, displayed and stored in a digital data recorder (RD-135T; TEAC) for off-line analysis. (2) Twobarrel micropipettes (5-10 $\mu \mathrm{m}$ in diameter) were used for blocking $\mathrm{nBOR} / \mathrm{nLM}$ or the raphe complex, one barrel of which was filled with $2 \mathrm{~m}$ sodium acetate and $2 \%$ pontamine sky blue to physiologically and anatomically confirm the electrode tip location, and the other contained GABA (100 mm, pH 3.3) or kainic acid (9.4 mm, pH 7.4; Sigma) and was connected to a pneumatic picopump (PV800; World Precision Instruments) for applying GABA $(0.08-0.12 \mu \mathrm{l})$ or kainic acid (0.2-0.3 $\mu \mathrm{l})$ (Gioanni et al., 1983; Gu et al., 2001; Cao et al., 2006; Yang et al., 2008). (3) A tungsten bipolar electrode was used for electrical stimulation of the left oculomotor nucleus and for electrolytic lesions of nLM/nBOR or the raphe complex as well. The poles of the bipolar electrode were glass-coated with $60 \mu \mathrm{m}$ length of tip exposed and separated by $400 \mu \mathrm{m}$ (Wang and Matsumoto, 1990; Cao et al., 2006; Yang et al., 2008). All microelectrodes were targeted according to the pigeon's brain atlas (Karten and Hodos, 1967). (4) Three steel electrodes (27 gauge syringe needles) were used for recording EOG signals, two of which were inserted into the anterior and posterior regions of the right orbital arch and the other as reference in the occipital bone (Wohlschläger et al., 1993; Yang et al., 2008). EOG 

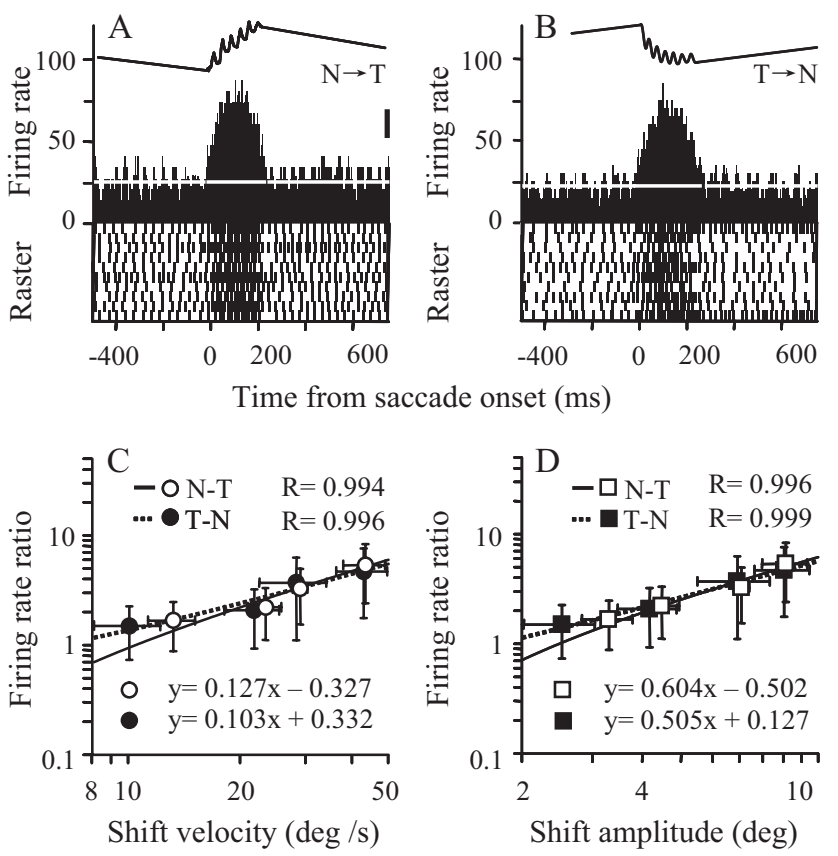

Figure 2. Sustained firing and its relationship to shift velocity and amplitude in ShN cells. $\boldsymbol{A}$, $\boldsymbol{B}$, A cell produced sustained firing accompanying $\mathrm{N}-\mathrm{T}$ and T-N saccades. Histograms are averaged for 10 repeats (time bin, $5 \mathrm{~ms}$ ) with raster display beneath. Enhancement of firing rates is determined by the rate higher than mean + SD (horizontal lines). C, D, The relationship between firing rate ratio of $\mathrm{ShN}$ cells $(n=10)$ and shift velocity $(\boldsymbol{C})$ and amplitude $(\boldsymbol{D})$ of eye position for N-T and T-N saccades is linearly fitted by a linear function $y=a x+b$, with $a$ and $b$ values and correlation coefficient $(R)$ being shown in $\boldsymbol{C}$ and $\boldsymbol{D}$ (log scales). Error bars indicate 1 SEM. Neuronal responses and saccades were elicited by motion of the grating at $8 \% \mathrm{~s}(\boldsymbol{A}, \boldsymbol{B})$ or $4-32^{\circ} / \mathrm{s}(\boldsymbol{C}, \boldsymbol{D})$. Scale bar, $5^{\circ}$.

signals were amplified (DC to $200 \mathrm{~Hz}$ ) and stored in the data recorder for off-line analysis together with single-cell recording data.

Antidromic stimulation and lesions. The tungsten bipolar electrode was stereotaxically placed in the left oculomotor nucleus [anterior (A), 2.7$3.2 \mathrm{~mm}$; lateral (L), $0.2 \mathrm{~mm}$; height $(\mathrm{H}), 6.2 \mathrm{~mm}$ ] to deliver rectangular current pulses of $100-300 \mu \mathrm{A}$ in intensity and $100 \mu \mathrm{s}$ in duration at 0.5 $\mathrm{Hz}$ (Wang and Matsumoto, 1990; Cao et al., 2006; Yang et al., 2008) for antidromic activation of internuclear neurons in the right abducens nucleus [A, $0.5 \mathrm{~mm}$; posterior (P), 0.5 mm; L, 0.5-1.0 mm; H, 4.0-4.8 mm]. For electrolytic lesions of neural structures under examination, the electrode was vertically inserted into $\mathrm{nBOR}(\mathrm{A}, 4.5-4.0 \mathrm{~mm} ; \mathrm{L}, 1.8 \mathrm{~mm} ; \mathrm{H}$, $4.0 \mathrm{~mm}$ ), or the raphe complex (A, $0.5 \mathrm{~mm}$;, $0.05 \mathrm{~mm}$; $\mathrm{L}, 0.0 \mathrm{~mm} ; \mathrm{H}$, $2.0-3.0 \mathrm{~mm}$ ) with its poles in a rostrocaudal arrangement. Its poles were arranged dorsoventrally and inserted laterally into nLM (A, $5.7 \mathrm{~mm}$; L, $4.0 \mathrm{~mm} ; \mathrm{H}, 4.5-5.5 \mathrm{~mm}$ ) to avoid accidentally stimulating the optic tectum (Cao et al., 2006). Each of the neural structures was lesioned sequentially at three sites by passing positive currents of $300 \mu \mathrm{A}$ for $10 \mathrm{~s}$ at each site because of their large size and irregular shape. Some recording sites were marked by applying positive currents of $30 \mu \mathrm{A}$ for $20-30 \mathrm{~s}$. Similarly, kainic acid $(0.2-0.3 \mu \mathrm{l})$ was pressure-injected into three sites in the neural structures each for 30-40 min to make chemical lesions. Recordings were made from the pigeon with chemical lesions after $5 \mathrm{~d}$ of survival (Yang et al., 2008).

At the end of experiments, each of the pigeons were killed by intraperitoneal injection of overdose urethane $(4 \mathrm{~g} / \mathrm{Kg})$. For those pigeons with a mark or lesion, their brains were removed from the skull and histologically processed for subsequent microscopic observations of marked and lesioned sites (Cao et al., 2004; Niu et al., 2006; Yang et al., 2008).

Data analysis. Spike data and eye positions were sampled at $8000 \mathrm{~Hz}$ around each saccade. Spikes were collected from $500 \mathrm{~ms}$ before to 1000 $\mathrm{ms}$ after the saccade, and those collected between 200 and $500 \mathrm{~ms}$ before the saccade were averaged as control. The onset and offset of saccades

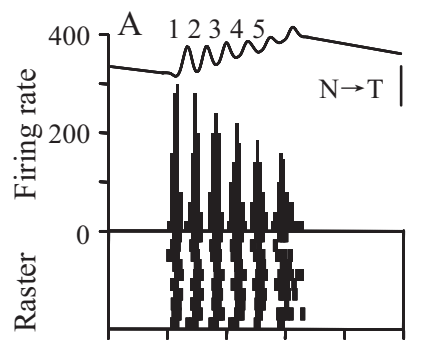

Time from saccade onset

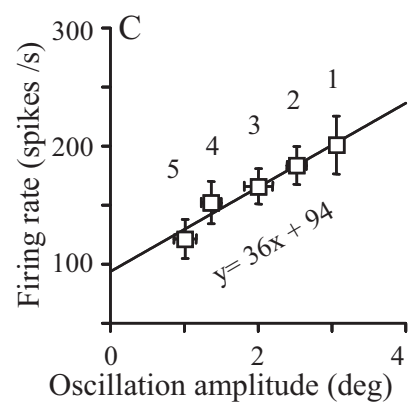

$0 \quad 100 \quad 200 \quad 300$

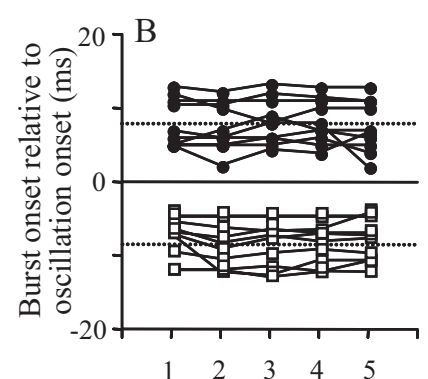

Ordinal number of oscillations

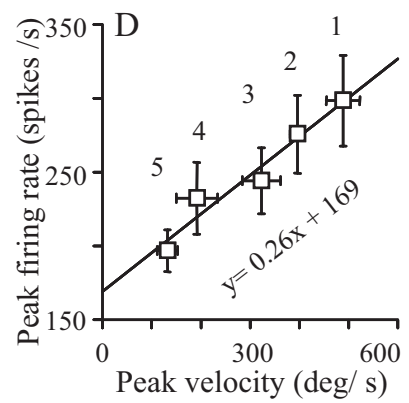

Figure 3. Bursting activity and its relationship to saccadic oscillations in $0 \mathrm{sN}$ cells. $\boldsymbol{A}$, A cell fired several bursts during saccades in $\mathrm{N}$-T direction, and its response histograms (bin, $5 \mathrm{~ms}$ ) are averaged for 10 repeats with raster display beneath. $B, 0$ sN cells could be distinctly divided into leading (open squares, $n=10$ ) and lagging (filled circles, $n=10$ ) groups according to burst onset relative to oscillation onset at zero. Horizontal dashed lines represent mean values $(-8.1$ vs $7.9 \mathrm{~ms}$ ). C, The amplitudes of saccadic oscillations are linearly related to the mean firing rates of cells in both groups, but a fitted curve for the leading group cells is shown for brevity. D, Peak velocity of oscillations is also linearly related to peak firing rate for this group of cells. These relations are fitted by a linear function $y=a x+b$, with a and $b$ values and correlation coefficient $(\boldsymbol{R})$ being shown in $\boldsymbol{B}-\boldsymbol{D}$. Statistics is made for the first five burst-oscillation pairs $(1-5)$ for brevity. The grating was moved at $8 \% / s(\boldsymbol{A})$ and $4-32 \%$ (B-D). Scale bar, $5^{\circ}$. Error bars indicate 1 SEM.

were determined with Cool Edit (Syntrillium Software) according to the characteristic $26 \mathrm{~Hz}$ oscillations in the saccade (Yang et al., 2008). The trough in EOG signals recorded during $\mathrm{N}-\mathrm{T}$ saccades or the crest in EOG signals recorded during $\mathrm{T}-\mathrm{N}$ saccades was used to determine the onset of a saccadic oscillation (see Figs. 1, 4). For calibration purposes, eye movements were videographed by an infrared video camera (DCR-HC40E; Sony) simultaneously with EOG recordings. The video images were used to calibrate EOG signals (Wohlschläger et al., 1993; Yang et al., 2008), revealing a sensitivity of $62-83 \mu \mathrm{V} / \mathrm{deg}$.

Spikes were collected before, during and after reversible inactivations of nBOR and nLM, or the raphe complex, and accumulated for $10-20$ repeats. Firing rates were averaged over a certain time bin ( 5 $\mathrm{ms}$ ) in each trial. We considered a firing rate to be either reduced or enhanced during saccades if it was lower or higher than the mean control rate by one SD. To normalize changes in the responses of different cells, we calculated the change ratio of firing rates, defined as $r=\left(f_{2}-f_{1}\right) / f_{1}$, where $f_{1}$ is intersaccadic firing rate as control and $f_{2}$ is firing rate during saccades.

\section{Results}

Among 297 cells recorded in the abducens nucleus, 216 cells were examined for their discharge patterns around the saccade, 40 cells for responses to antidromic stimulation of the oculomotor nucleus, and 41 others for effects of blockade of the optokinetic nuclei or the raphe complex on firing activity accompanying saccadic shift and/or oscillations.

\section{Classification of abducens neurons}

Electrooculogram traces in Figure 1 show that a saccadic eye movement consists of a shift of eye position and several cycles of 
oscillation. When the pigeon viewed stationary gratings, its spontaneous saccade had a peak speed of $485 \pm 60 \%$ s and duration of $242 \pm 36 \mathrm{~ms}$ with $6.4 \pm 1.0$ cycles of oscillation (mean $\pm \mathrm{SD}, n=600$ ) (Yang et al., 2008). Abducens cells recorded were classified into three types according to their discharge patterns accompanying saccadic shift and/or oscillations. Fiftynine cells $(27 \%)$ were spontaneously active (28 \pm 11 spikes/s) and discharged sustained firing at higher rates around the shift, thus referred to as a shift-related neuron (ShN) (Figs. 1A, 2A,B). When saccades were induced by the grating moved at $4-32^{\circ} / \mathrm{s}$, the shift velocity was increased as firing rates in $\mathrm{ShN}$ cells were enhanced. The relationship between the firing rate ratio (see Materials and Methods) and the shift velocity and amplitude was linearly described in Figure 2, $C$ and $D$. These cells enhanced sustained firing $20 \pm 11 \mathrm{~ms}$ before the onset of shift for $\mathrm{N}$-T saccades and $21 \pm 12 \mathrm{~ms}(n=40)$ for $\mathrm{T}-\mathrm{N}$ saccades, and this enhanced firing returned to normal as the shift terminated. Their average firing rate (paired $t$ test, $t=1.130, p=0.288 ; n=$ $10)$ and firing duration $(t=0.459, p=$ $0.657 ; n=10$ ) were not different for N-T versus $\mathrm{T}-\mathrm{N}$ saccades.

Ninety-three oscillation-related neurons (OsNs; 43\%) had no spontaneous activity and produced several bursts (approximately five spikes per burst) at $26.1 \pm 2.1 \mathrm{~Hz}(n=50)$ corresponding to cycles of oscillation (Figs. 1B, 3A). Thirtythree of them were analyzed for N-T saccades (lateral rectus muscles contract) and classified into two groups according to temporal relation: 22 cells fired bursts before the onset of oscillations (leading group), and 11 others fired bursts after the onset of oscillations (lagging group). This classification is distinctly shown in Figure $3 B$, indicating that cells in the leading group fired bursts $8.1 \mathrm{~ms}$ before and those in the lagging group fired $7.9 \mathrm{~ms}$ after the onset of oscillations. Here, all data analyses were made for the first five burst/oscillation pairs for brevity. The amplitude of saccadic oscillations was reduced as the mean firing rate in bursts decreased, and their relationship is linearly fitted (Fig. 3C). Similarly, the peak velocity of saccadic oscillations was also reduced as the peak firing rate in bursts decreased, and their relationship is well correlated (Fig. 3D). It is interesting to note that temporal relationship between the onset of bursts and the onset of oscillations for T-N saccades (medial rectus muscles contract) was opposite to
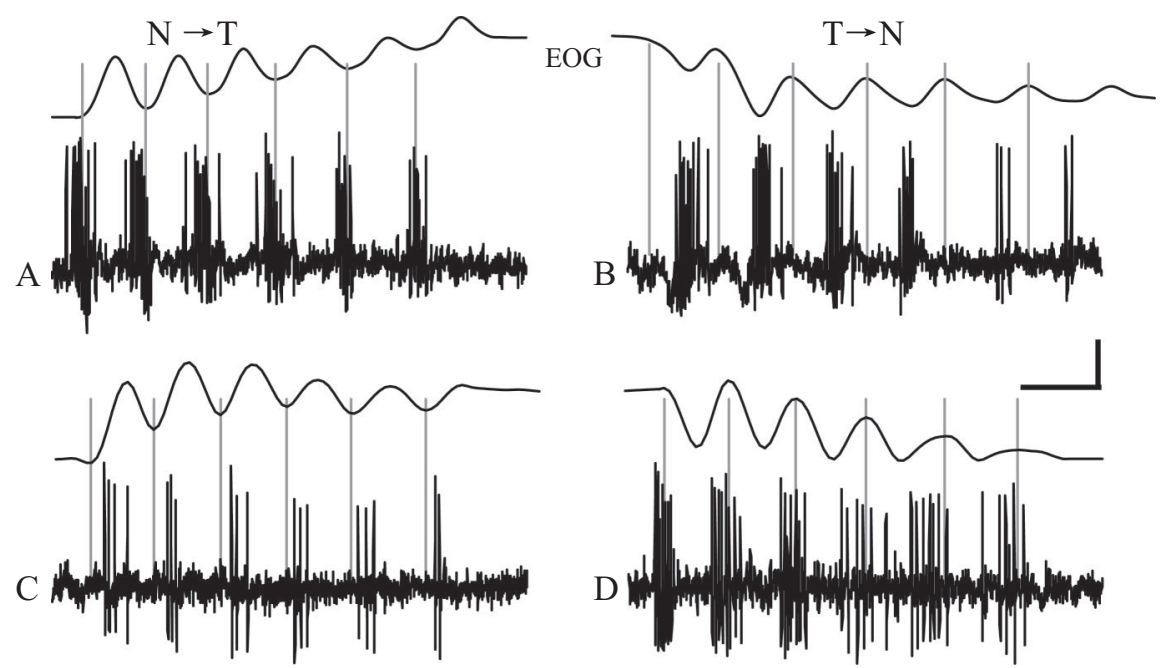

Figure 4. Temporal relationship between the onset of bursts and that of oscillations in 0 SN cells depends on saccadic direction. $\boldsymbol{A}, \boldsymbol{B}$, Cell AB began bursting before the onset of oscillations for $\mathrm{N}$-T saccades $(\boldsymbol{A})$ but after the onset of oscillations for T-N saccades (B). C, D, In contrast, cell CD started bursting after the onset of oscillations for $\mathrm{N}$-T saccades ( $\boldsymbol{C}$ ) but before the onset of oscillations for T-N saccades $(\boldsymbol{D})$. Recordings were made from the pigeon viewing stationary gratings. Vertical gray lines symbolize the onset of oscillations. Calibration: $2^{\circ}$ for EOG or $20 \mu \mathrm{V}$ for spikes, $60 \mathrm{~ms}$.
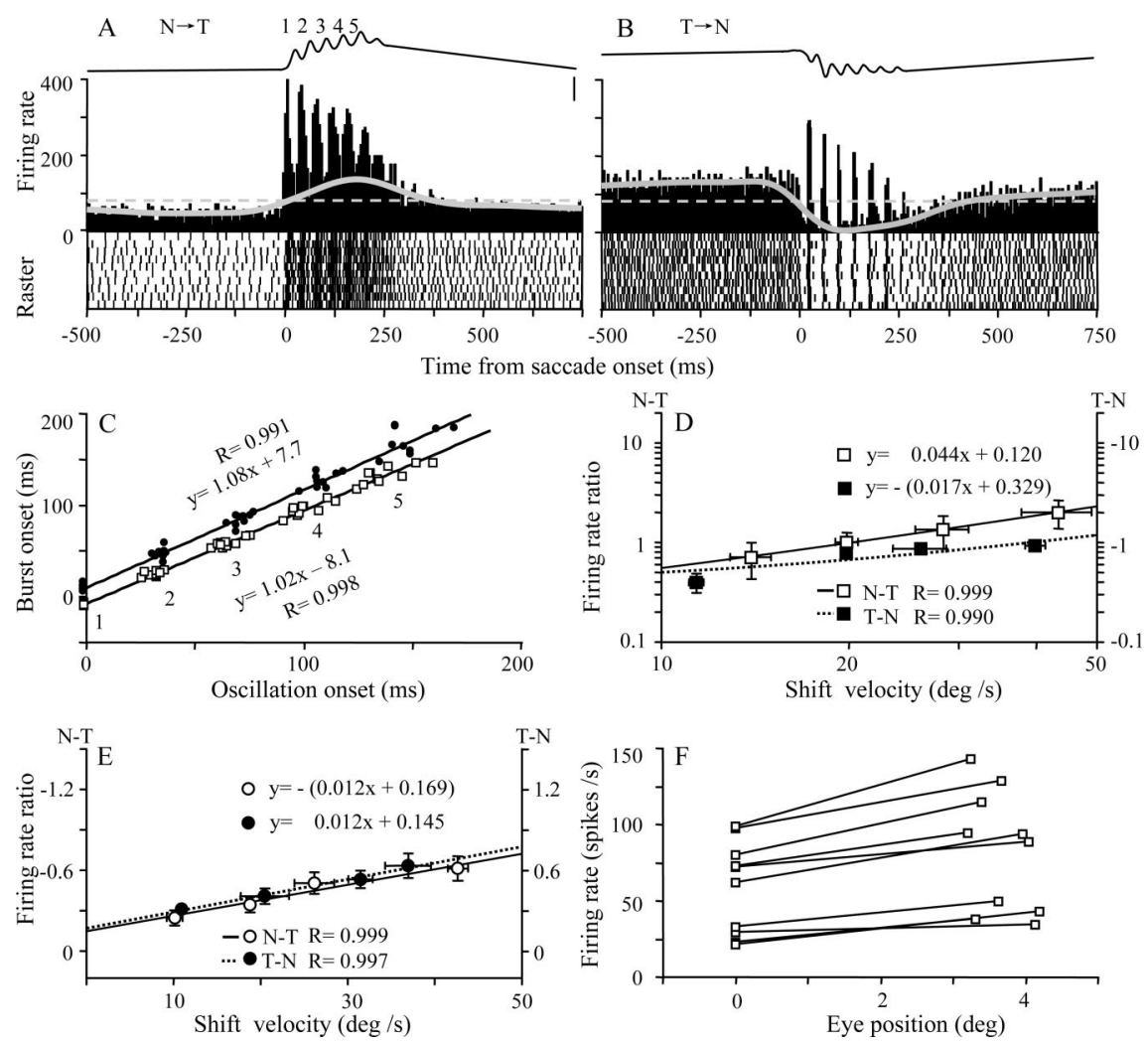

Figure 5. Firing activity and statistic analysis of SaN cells. $\boldsymbol{A}, \boldsymbol{B}, \mathrm{A}$ cell began bursting before the onset of oscillations and enhanced sustained firing for $\mathrm{N}-\mathrm{T}$ saccades $(\boldsymbol{A})$, but started bursting after the onset of oscillations and reduced sustained firing for T-N saccades $(\boldsymbol{B})$. Its histograms are averaged for 10 repeats (bin, $5 \mathrm{~ms}$ ) with raster display beneath. Its sustained rates are fitted by cubic spline interpolation (gay curves). Horizontal lines represent the spontaneous rate. The temporal relationship between the onset of bursts and that of oscillations is described by linear functions for the leading (squares, $n=10$ ) and lagging (circles, $n=$ 10) groups ( $\boldsymbol{C}$. $\boldsymbol{D}, \boldsymbol{E}$, Eye shift velocity is linearly related to the firing rate ratio in the leading ( $\boldsymbol{D}$, log scales) and lagging $(\boldsymbol{E})$ groups for N-T (open symbols) and T-N (filled symbols) saccades. These fitted lines are described by a function $y=a x+b$ with $a$ and $b$ values and correlation coefficient $(R)$ being shown in $\boldsymbol{C}-\boldsymbol{E}$. Eye position is also correlated with sustained firing rates (averaged for 10 repeats) during steady fixation when the pigeon made spontaneous saccades $(\boldsymbol{F})$. The grating was moved at $8^{\circ} / \mathrm{s}(\boldsymbol{A}, \boldsymbol{B})$ or $4-32^{\circ} / \mathrm{s}(\boldsymbol{C}-\boldsymbol{E})$. Scale bar, $5^{\circ}$. Error bars indicate 1 SEM. 
that for $\mathrm{N}-\mathrm{T}$ saccades. For example, the leading group cells began bursting $8.1 \pm$ $1.4 \mathrm{~ms}$ before the onset of oscillations for $\mathrm{N}$-T saccades, but $10.5 \pm 1.4 \mathrm{~ms}(n=10$ cells $\times 5$ oscillations) after the onset of oscillations for $\mathrm{T}-\mathrm{N}$ saccades (Fig. $4 A, B)$, whereas the lagging group cells began bursting $7.9 \pm 1.3 \mathrm{~ms}$ after the onset of oscillations for N-T saccades but $11.1 \pm 1.3 \mathrm{~ms}$ before the onset of oscillations for T-N saccades $(n=10 \times$ 5) (Fig. 4C,D).

Sixty-four saccade-related neurons (SaNs; 30\%) were spontaneously active ( $58 \pm 28$ spikes/s) and produced both sustained firing and several bursts around the saccade (Figs. $1 C$ and 5A, B). They fired bursts at a frequency identical to that of saccadic oscillations $(26.3 \pm 2.1$ vs $26.2 \pm$ $2.0 \mathrm{~Hz}, n=50$ ), and their sustained firing lasted $257 \pm 114 \mathrm{~ms}(n=10)$ after the saccade end. Similar to OsNs, 21 SaNs examined in detail were also divided into two groups according to temporal relationship between the onset of bursts and that of oscillations for N-T saccades. The leading group contained 11 cells which fired bursts $8.1 \pm 1.2 \mathrm{~ms}$ before the onset of oscillations; the lagging group included 10 cells that fired bursts $7.7 \pm 1.4 \mathrm{~ms}$ after the onset of oscillations. This temporal relationship was described by linearly fitted lines with intercept of $-8.1 \mathrm{~ms}$ for the leading group and $7.7 \mathrm{~ms}$ for the lagging group (Fig. $5 C$ ). The shift velocity of eye position was increased as the firing rate ratio in abducens cells enhanced, and their relationship for N-T and T-N saccades was described by linearly fitted curves plotted for the leading group (Fig. 5D) and for the lagging group (Fig. 5E). Meanwhile, sustained firing in these cells was enhanced for $\mathrm{N}-\mathrm{T}$ saccades and reduced for $\mathrm{T}-\mathrm{N}$ saccades in the leading group (Fig. 5A,B), whereas opposite changes in firing activity occurred in the lagging group. For example, sustained firing began $8.3 \pm 5.6 \mathrm{~ms}$ before the saccade onset and its rate was increased from $58 \pm 28$ to $107 \pm 24$ spikes/s when $\mathrm{N}-\mathrm{T}$ saccades were induced by motion of grating at $8 \%$ s. In contrast, this firing activity started $8.3 \pm 4.3 \mathrm{~ms}$ before the saccade onset and its rate was reduced from $58 \pm 28$ to $15 \pm 10$ spikes/s ( $n=10)$ during T-N saccades. Furthermore, we examined relationship between horizontal eye positions and sustained firing rates in 10 SaNs. Firing rates were averaged within $250 \mathrm{~ms}$ during steady fixation (primary eye position at zero) and within $250 \mathrm{~ms}$ after a saccade (new eye position) for 10 repeats, showing that mean firing rates in SaNs were correlated with horizontal eye position during steady fixation (Fig. $5 F$ ).
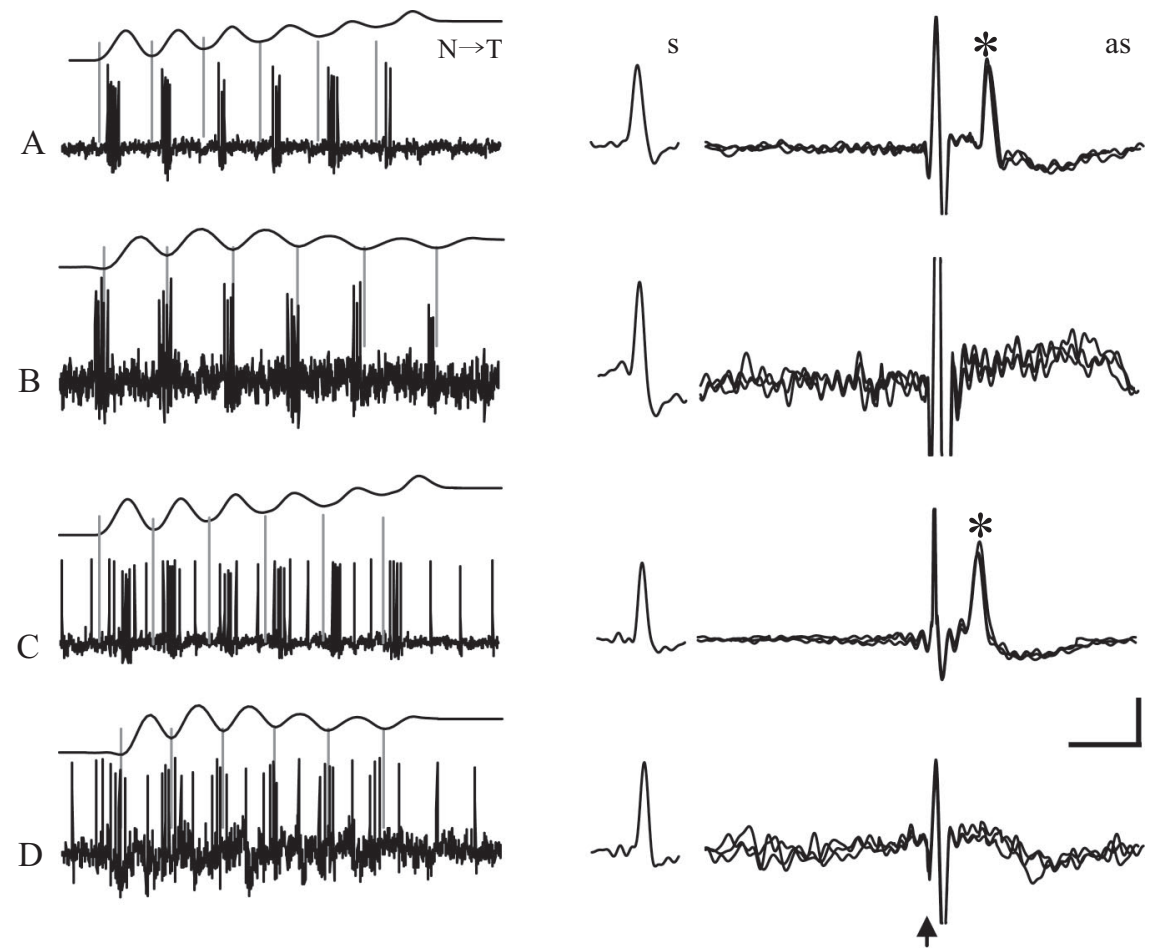

Figure 6. Internuclear abducens neurons identified by antidromic stimulation of the contralateral oculomotor nucleus. $A-D$, Firing patterns of two 0 sNs $(\boldsymbol{A}, \boldsymbol{B})$ and two SaNs $(\boldsymbol{C}, \boldsymbol{D})$ accompanying $\mathrm{N}$-T saccades while the pigeon viewed stationary gratings. The onset of bursts started after $(\boldsymbol{A}, \boldsymbol{C})$ or before $(\boldsymbol{B}, \boldsymbol{D})$ the onset of saccadic oscillations (vertical gray lines). Column s displays a single spike in bursts for comparison with an antidromically activated spike (asterisks) in column as, which shows responses of abducens neurons to antidromic stimulation (3 repeats). All of the recordings in the same row were obtained from the same cell. The arrow points to electrical stimulation artifacts. Calibration: $3^{\circ}$ for $E 0 G ; A, B, 65 \mu V ; C, D, 25 \mu V ; A-D, 50 \mathrm{~ms} ; 5$, as, $2 \mathrm{~ms}$.

$$
\mathrm{nBOR}+\mathrm{nLM}
$$

Raphe
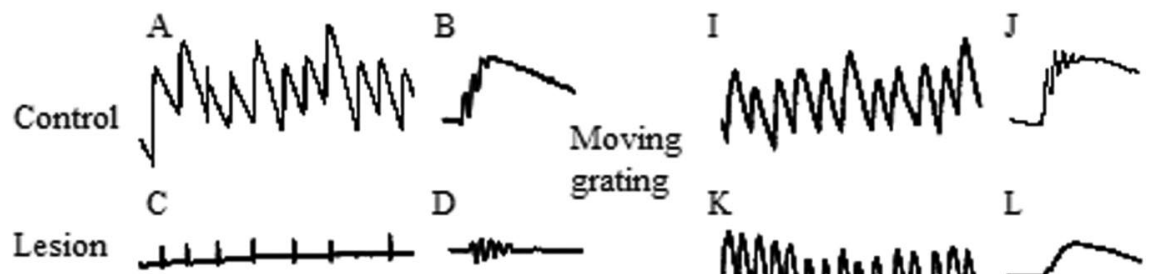

$\mathrm{K}$

L
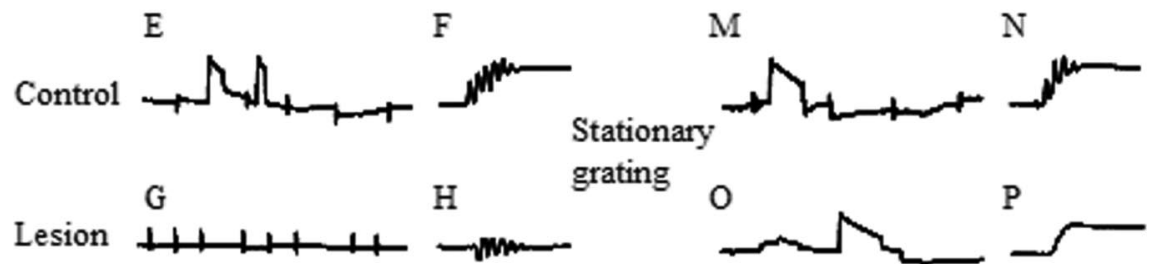

Figure 7. Effects of electrolytic lesions of the optokinetic nuclei and the raphe complex on eye movements identified by EOG. $A-H$ After lesions of both $\mathrm{nBOR}$ and $\mathrm{nLM}$, the shift component of optokinetic and spontaneous saccades $(\boldsymbol{A}-\boldsymbol{H})$ and the slow phase of OKN $(\boldsymbol{A}-\boldsymbol{D})$ were eliminated whereas saccadic oscillations remained unchanged. $I-\boldsymbol{P}$, In contrast, raphe lesions abolished saccadic oscillations, but did not affect the shift component of optokinetic and spontaneous saccades $(I-P)$ and the slow phase of OKN $(I-L)$. The pigeons viewed stationary gratings for recording spontaneous saccades before and after lesions, which were moved at $16^{\circ} / \mathrm{s}$ in the temporonasal direction to induce $0 \mathrm{KN}$. Calibration: $5^{\circ}$ for EOG; 1 s in the first and third columns, 0.1 s in others.
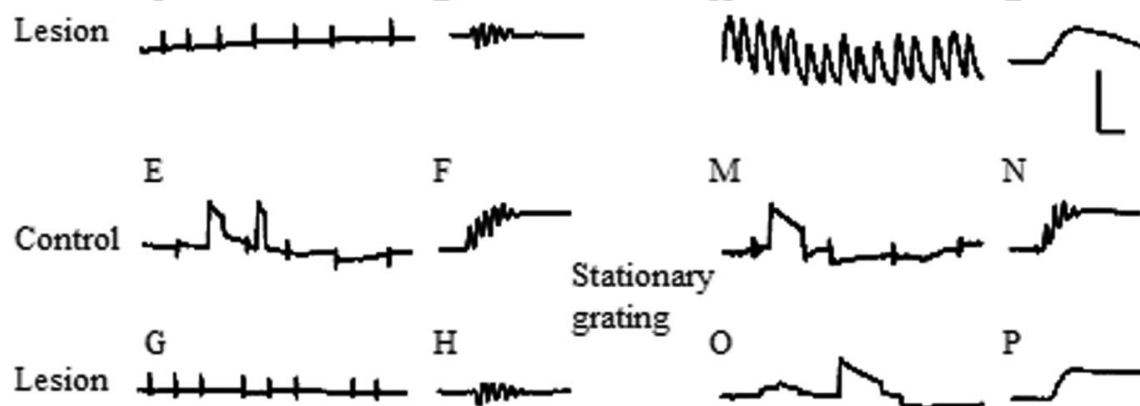

\section{(1)}


antidromic stimulation of the oculomotor nucleus. None of the 6 ShNs responded to the antidromic stimulation. The 19 OsNs included 8 cells in the leading group and 11 in the lagging group. Eight of the 11 lagging group cells were activated by antidromic stimulation with latency of $1.2 \pm 0.3 \mathrm{~ms}$ (Fig. $6 A$ ), whereas none of the 8 leading group cells responded to antidromic stimulation (Fig. 6 B). Similarly, the 15 SaNs were also divided into the leading group ( 6 cells) and lagging group ( 9 cells). Six of the 9 lagging group cells were antidromically activated with latency of $1.3 \pm$ $0.3 \mathrm{~ms}$ (Fig. $6 C$ ), whereas none of the 6 leading group cells responded to antidromic stimulation of the oculomotor nucleus (Fig. 6D).

\section{Differential origins of saccadic shift and oscillations}

Because discharge patterns in abducens cells are related to saccadic shift and/or oscillations that may originate from different sources, we examined the effects of inactivating the optokinetic nuclei and the raphe complex on abducens activity and eye movements. After electrolytic lesions of both nBOR and nLM in three pigeons, the slow phase of OKN and saccadic shift in each of the pigeons were abolished whereas saccadic oscillations remained unchanged (Fig. 7A-H). When N-T saccades were induced by motion of the grating at velocities of $2-128 \%$, data analysis indicated that shift velocity was reduced by $91 \pm 3 \%(n=21)$, whereas oscillation velocity remained unchanged (paired $t$ test, $t=0.61, p=0.56 ; n=21$ ). Meanwhile, 13 OsNs and SaNs, but no ShNs, were recorded from the pigeons, with sustained activity in SaNs being reduced to a great extent. In contrast, lesions of the raphe complex were made in additional three pigeons, each of which eliminated saccadic oscillations but the slow phase of $\mathrm{OKN}$ and saccadic shift remained (Fig. 7I-P). Raphe lesions reduced oscillation velocity by $95 \pm 0.3 \%(n=21)$ but did not change shift velocity (paired $t$ test, $t=1.18, p=0.28 ; n=21$ ). Meanwhile, eight ShNs and SaNs but no OsNs were recorded in all of these pigeons, with bursting activity in SaNs being reduced obviously.

To exclude a possibility that the effects of electrolytic lesions might be caused by damage to fibers of passage (Gioanni et al., 1983) through the optokinetic nuclei or the raphe complex, we injected kainic acid $(0.2-0.3 \mu \mathrm{l})$ to destroy cell bodies in these structures. The results obtained with chemical lesions were similar to those with electrolytic lesions. For example, when N-T saccades were induced by motion of the grating at $16 \%$, chemical lesions of both the nBOR and nLM in two pigeons reduced shift velocity by $85 \%$ and did not change oscillation velocity (paired $t$ test, $t=0.76, p=0.45 ; n=100$ ). In contrast, raphe lesions made in additional two pigeons resulted in reduction of oscillation velocity by $96 \%$, but no change in shift velocity (paired $t$ test, $t=$ $1.50, p=0.94 ; n=100)$. Together, it appears that saccadic shift and the slow phase of OKN both originate from the optokinetic nuclei $\mathrm{nBOR} / \mathrm{nLM}$, whereas saccadic oscillations originate from the brainstem raphe complex.

\section{Effects of optokinetic and raphe blockade on abducens activity}

To further provide evidence of whether sustained and burst activity in abducens cells may also originate from the optokinetic nuclei and/or the raphe complex, we examined the effects of optokinetic or raphe blockade on firing activity of abducens neurons. After simultaneous blockade of $\mathrm{nBOR}$ and $\mathrm{nLM}$ with GABA $(0.08-0.12 \mu \mathrm{l})$, the firing rate ratio in ShNs was reduced by $51 \pm$ $20 \%(n=4)$ (Fig. $8 A)$. Similarly, the firing rate ratio of sustained activity in SaNs was reduced by $51 \pm 33 \%$, but that of burst
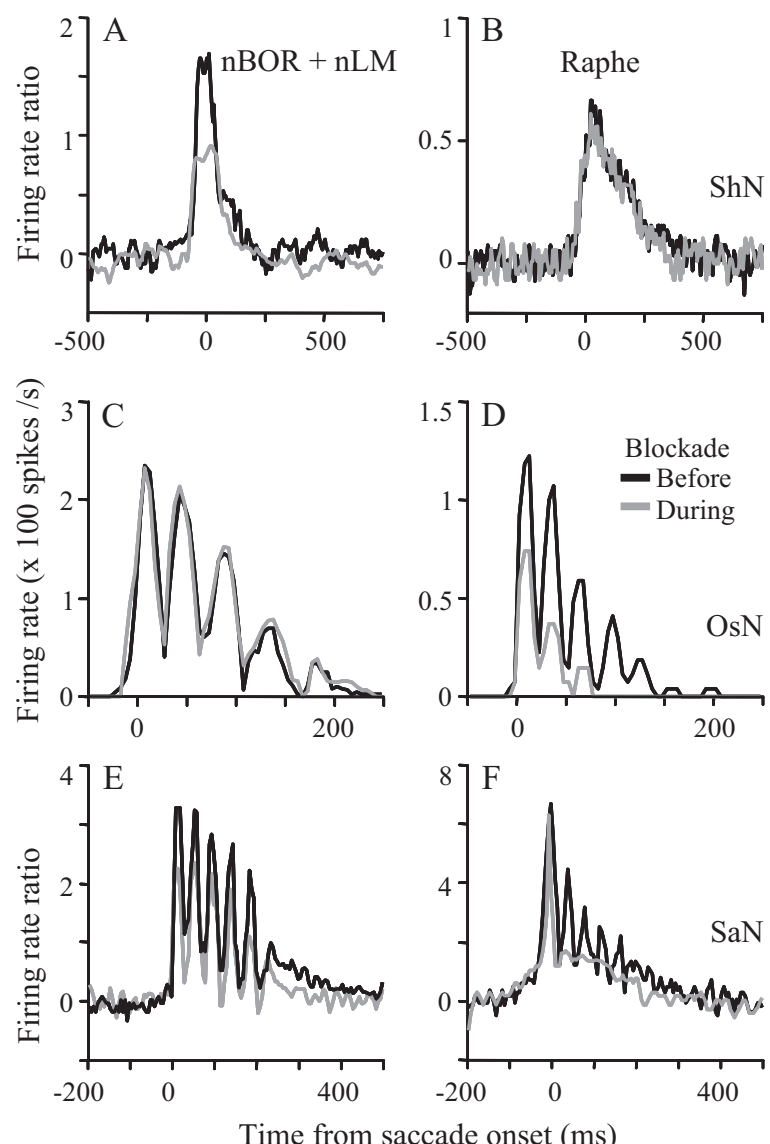

Figure 8. Histograms show effects of blocking the optokinetic nuclei and the raphe complex on firing activity in three types of abducens neurons. $\boldsymbol{A}, \boldsymbol{C}, \boldsymbol{E}$, Blockade of activity in both $\mathrm{nBOR}$ and $\mathrm{nLM}(\mathrm{GABA}, 0.1 \mu \mathrm{l})$ reduced sustained firing in $\operatorname{ShN}(\boldsymbol{A})$ and SaN $(\boldsymbol{E})$ cells but not bursting activity in 0 sNs $(\boldsymbol{C}), \boldsymbol{B}, \boldsymbol{D}, \boldsymbol{F}$, In contrast, raphe blockade reduced bursting activity in $0 \mathrm{sNs}(\boldsymbol{D})$ and SaNs $(\boldsymbol{F})$ but not sustained activity in ShNs $(\boldsymbol{B})$ and SaNs $(\boldsymbol{F})$. Black and gray histograms are obtained before and during blockade, respectively. Note that ordinates in $\boldsymbol{A}, \boldsymbol{B}, \boldsymbol{E}$, and $\boldsymbol{F}$ are scaled for the firing rate ratio, but those in $\boldsymbol{C}$ and $\boldsymbol{D}$ for firing rates because 0 sNs were not spontaneously active. Time bin, $5 \mathrm{~ms}$.

activity was not changed (paired $t$ test, $t=0.90, p=0.46 ; n=3$ ) (Fig. $8 E$ ). Because OsNs had no spontaneous activity and thus their changes in firing activity could only be described by the firing rate (Fig. $8 C, D$ ). The firing rate of bursts in OsNs was not changed during blockade of both optokinetic nuclei (paired $t$ test, $t=0.35, p=0.74 ; n=10$ ) (Fig. 8C). Meanwhile, blockade of both $\mathrm{nBOR}$ and $\mathrm{nLM}$ reduced the velocity of saccadic shift by $\sim 50 \%$ but did not change the velocity of saccadic oscillations (paired $t$ test, $t=1.37, p=0.18 ; n=50$ ). In contrast, raphe blockade reduced burst activity, but not sustained firing in abducens neurons. Raphe blockade reduced the firing rate of bursts in OsNs by $47 \pm 23 \%(n=10)$ (Fig. $8 D)$ and the firing rate ratio of bursts in SaNs by $25 \pm 15 \%(n=3)$ (Fig. $8 F)$. However, the firing rate ratio of sustained activity in ShNs (paired $t$ test, $t=1.11, p=$ $0.33 ; n=5$ ) (Fig. $8 B$ ) and that of sustained activity in SaNs (paired $t$ test, $t=0.79, p=0.51 ; n=3$ ) (Fig. $8 F$ ) were not changed. In the meantime, raphe blockade reduced the velocity of saccadic oscillations by $\sim 40 \%$ but did not change the velocity of saccadic shift (paired $t$ test, $t=0.88, p=0.39 ; n=50$ ).

\section{Histological confirmation}

The recording sites of 37 neurons including 5 ShNs, 15 OsNs, 11 SaNs, and 6 internuclear neurons were marked and all were lo- 
calized within the abducens nucleus with an intermingled distribution. The electrical stimulation sites were marked in three pigeons and all were localized in the oculomotor nucleus. Twenty-three GABAapplication sites were marked in $\mathrm{nBOR}$ (eight), nLM (nine), and in the raphe complex (six). In addition, electrolytic lesions were made in the optokinetic nuclei $\mathrm{nLM} / \mathrm{nBOR}$ (three pigeons) and the raphe complex (three pigeons) (Fig. 9). In kainate-lesioned pigeons, cell bodies in $\mathrm{nLM} / \mathrm{nBOR}$ (two pigeons) and in the raphe complex (two pigeons) disappeared (Fig. 10). In all of these cases, the lesioned volume occupied $75 \pm 6 \%$ of the normal volume for a neural structure under study $(n=15)$, which was obtained by (rostrocaudal extent $\times$ mediolateral extent $\times$ dorsoventral extent of the lesioned region) divided by (rostrocaudal extent $\times$ mediolateral extent $\times$ dorsoventral extent of the normal structure). Because these structures are irregular in shape, their surrounding structures were probably lesioned to some extent. However, the effects of electrolytic and chemical lesions and those of GABA blockade we observed were all consistent, implying that a small damage, if any, to the surrounding structures did not influence the results.

\section{Discussion}

The present study is the first to provide evidence that abducens neurons in birds produce sustained discharge and/or several bursts accompanying the shift and oscillation components of saccades, and sustained and bursting activity originate from the optokinetic nuclei and the brainstem raphe complex, respectively.

The first finding of the present study is that there exist at least three types of neurons in the pigeon abducens nucleus. Among them, ShNs may not innervate the lateral or medial rectus muscles because they fire quite earlier than the onset of saccades and equally for N-T and T-N saccades. In addition, none of ShNs could be activated by antidromic stimulation of the contralateral oculomotor nucleus. Thus, it is likely that they would send signals to a brain region as the flocculus-projecting neurons in the primate abducens nucleus (Büttner-Ennever, 2005). Previous studies have found a group of saccade-related neurons in the chicken trochlear nucleus (Wallman et al., 1994), but they are similar behaviorally to OsNs we found in the pigeon abducens nucleus. Furthermore, OsNs in the pigeon are divided into two groups according to temporal relationship between the onset of bursts and that of oscillations for N-T saccades. The leading group cells fire bursts $8.1 \mathrm{~ms}$ before the onset of oscillations and none of them could be activated by antidromic stimulation of the oculomotor nucleus. This leading time is similar to a delay time at which electrical stimulation of the pigeon abducens nucleus initiates eye movements (McVean and Stelling, 1986). However, the lagging group cells fire bursts $7.9 \mathrm{~ms}$ after the onset of oscillations and most of them could be activated by antidromic stimulation of the oculomotor nucleus, proving that they are internuclear abducens neurons, which indirectly control the medial rectus muscles of the contralateral eye. Such OsN grouping and time courses are also held for bursting activity in SaNs. It appears that abducens neurons and internuclear abducens neurons fire in a similar pattern but time courses are out of phase, implying that movements of both eyes in birds are uncoordinated, as shown behaviorally (Bloch et al., 1984; Wallman and Pettigrew, 1985). The ratio of the leading group neurons to the lagging group neurons is similar to that of abducens neurons labeled by HRP injections into the lateral rectus muscle to internuclear abducens neurons labeled by HRP injections into the contralateral oculomotor nucleus (Cabrera et al., 1989). However, a small proportion of neurons in the lagging group failed to be antidromically activated, probably because of the electrode out of register with the neuron under examination. Moreover, it is interesting to note that sustained firing in SaNs would be able to change eye position and maintain the eyes for a brief fixation, in accordance with our EOG traces and other eye movement recordings in the pigeon (Nye, 1969; Wallman and Pettigrew, 1985).

The second finding is that sustained and bursting discharges of abducens neurons or shift and oscillation components of a saccadic eye movement originate from the optokinetic nuclei $\mathrm{nBOR} / \mathrm{nLM}$ and the saccade-related raphe complex, respectively. This conclusion is supported by the finding that lesions of nBOR/ nLM eliminated saccadic shift and the slow phase of OKN but left saccadic oscillations unchanged, whereas lesions of the raphe complex abolished saccadic oscillations but did not change saccadic shift and the slow phase of OKN. Meanwhile, optokinetic and raphe lesions also reduced or eliminated shift-related and oscillation-related firing in abducens cells, respectively. Furthermore, blockade of nBOR/nLM by GABA reduced shift-related activity, whereas raphe blockade reduced oscillation-related activity in abducens neurons. Under these circumstances, saccadic shift was also reduced by optokinetic blockade and saccadic oscillations were reduced by raphe blockade. It seems that the effects of electrolytic lesions are stronger than those of GABA blockade because electrolytic lesions are extensive and permanent but GABA blockade is usually local and would recover in 


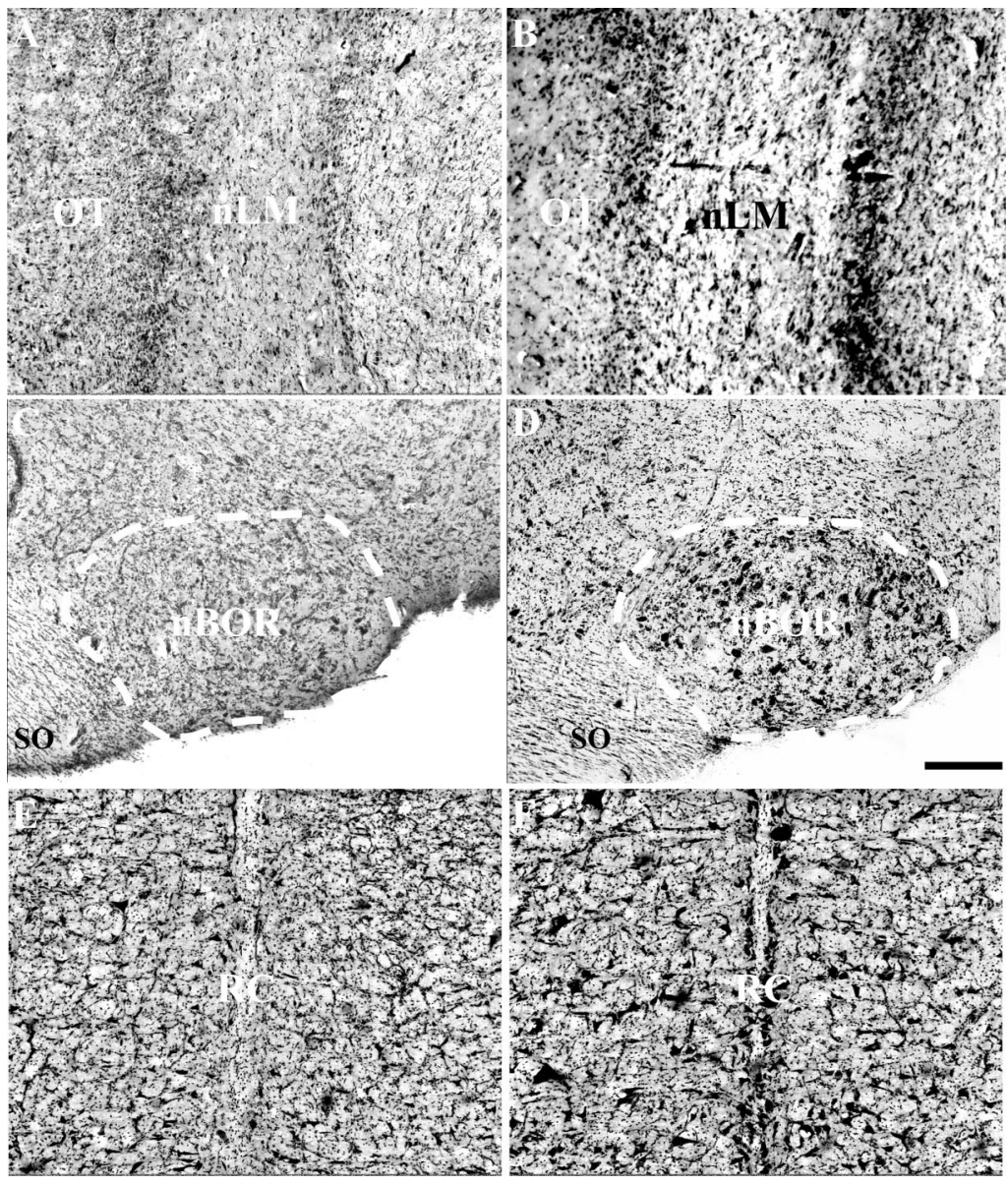

Figure 10. $A-F$, Photomicrographs of the pigeon brain cross-sections show kainic acid lesions of the $\mathrm{LLM}$ at $\mathrm{A} 5.75 \mathrm{~mm}(\boldsymbol{A})$, nBOR at $A 4.50 \mathrm{~mm}(\boldsymbol{C})$, and raphe complex (RC) at $\mathrm{A} 0.25 \mathrm{~mm}(\boldsymbol{E})$ and their control sections corresponding to $\boldsymbol{B}, \boldsymbol{D}$, and $\boldsymbol{F}$, respectively. Lesioned sections clearly show that almost all cell bodies in these structures were destroyed by the acid. For abbreviations and histological procedures, see Figure 9 . Scale bar, $200 \mu \mathrm{m}$.

10-15 min. Recently, we found early- and late-omnipause neurons in the pigeon raphe complex, which project respectively to the $\mathrm{nBOR}$ and $\mathrm{nLM}$, indicating that saccade-related signals are transmitted from the raphe complex to the optokinetic nuclei (Yang et al., 2008).

Horizontal eye movements in birds and mammals are similar in that they are actuated by the lateral and medial rectus muscles innervated by the abducens and oculomotor nuclei, but different in that a saccade in mammals is a rapid shift of eye position, whereas that in all species of birds examined to date consists of a shift of eye position and several cycles of oscillation (Pettigrew et al., 1990; Wallman et al., 1994; Niu et al., 2006; Yang et al., 2008), regardless of the number of foveae in each eye, because many birds such as the pigeon have a single fovea (Nalbach et al., 1990; Letelier et al., 2004) but birds of prey possess two foveae in each eye (Tucker, 2000). It is suggested that saccadic oscillations may diffuse oxygen and nutrients through the pecten, a comb-like vascular structure projecting into the vitreous, and stir the vitreous to facilitate this diffusion, as well as play a role in gaze shift behaviors (Pettigrew et al., 1990; Wallman et al., 1994). The present study found that saccadic oscillations in birds originate from the brainstem raphe complex and thus may constitute the neuronal basis for the diffusion and gaze shift. However, saccades in mammals originate from several midbrain and brainstem structures and serve to rapidly shift the gaze (Fuchs et al., 1985; Fukushima et al., 1992; Moschovakis et al., 1996; Moschovakis,
1997; Sparks, 2002). It is noteworthy that the quick phase of OKN also originates from the raphe complex in the pigeon; thus, it is a form of saccades. Similarly, a saccade and the quick phase of OKN in mammals may also originate from the same structures.

All abducens neurons recorded in mammals fire in the form of pulse step (Fuchs and Luschei, 1970; Schiller, 1970; Delgado-Garcia et al., 1986; Stahl and Simpson, 1995), whereas abducens neurons recorded in birds discharge sustained firing and/or several bursts. The present study revealed that sustained firing in abducens cells originates from the OKNrelated $\mathrm{nLM} / \mathrm{nBOR}$, whereas bursting activity originates from the saccade-related raphe complex. The nLM and nBOR in nonmammals such as birds are respectively comparable with the nucleus of the optic tract and the terminal nuclei of the accessory optic tract in mammals (Fite, 1985; McKenna and Wallman, 1985), and the brainstem raphe complex in birds may be comparable with the nucleus raphe interpositus in primates because both brainstem structures are located around the midline in the pontine reticular formation and characterized by saccade-related omnipause neurons (Kaneko, 1996; Horn, 2005; Yang et al., 2008). Although several midbrain and brainstem structures are involved in phasic or tonic signals (Fuchs et al., 1985; Fukushima et al., 1992; Moschovakis et al., 1996; Moschovakis, 1997; Sparks, 2002), these OKN-related and omnipause neuron-containing structures in mammals may also contribute to phasic and tonic signals generating saccades.

\section{References}

Bloch S, Rivaud S, Martinoya C (1984) Comparing frontal and lateral viewing in the pigeon. III. Different patterns of eye movements for binocular and monocular fixation. Behav Brain Res 13:173-182.

Brecha N, Karten HJ (1979) Accessory optic projections upon oculomotor nuclei and vestibulocerebellum. Science 203:913-916.

Büttner-Ennever JA (2005) The extraocular motor nuclei: organization and functional neuroanatomy. Prog Brain Res 151:95-125.

Büttner-Ennever JA, Horn AK (1997) Anatomical substrates of oculomotor control. Curr Opin Neurobiol 7:872-879.

Cabrera B, Pásaro R, Delgado-Garcia JM (1989) Cytoarchitectonic organization of the abducens nucleus in the pigeon (Columbia livia). J Anat 166:203-211.

Cao P, Gu Y, Wang SR (2004) Visual neurons in the pigeon brain encode the acceleration of stimulus motion. J Neurosci 24:7690-7698.

Cao P, Yang Y, Yang Y, Wang SR (2006) Differential modulation of thalamic neurons by optokinetic nuclei in the pigeon. Brain Res 1069:159-165.

Delgado-Garcia JM, del Pozo F, Baker R (1986) Behavior of neurons in the abducens nucleus of the alert cat-I. Motoneurons. Neuroscience 17:929-952.

Donaldson IM, Knox PC (1991) Afferent signals from pigeon extraocular muscles modify the vestibular responses of units in the abducens nucleus. Proc Biol Sci 244:233-239.

Evinger C (1988) Extraocular motor nuclei: location, morphology and afferents. In: Neuroanatomy of the oculomotor system (Büttner-Ennever JA, ed), pp 81-117. Amsterdam: Elsevier. 
Fite KV (1985) Pretectal and accessory-optic visual nuclei of fish, amphibia and reptiles: theme and variations. Brain Behav Evol 26:71-90.

Fite KV, Reiner A, Hunt SP (1979) Optokinetic nystagmus and the accessory optic system of pigeon and turtle. Brain Behav Evol 16:192-202.

Fu YX, Gao HF, Guo MW, Wang SR (1998) Receptive field properties of visual neurons in the avian nucleus lentiformis mesencephali. Exp Brain Res 118:279-285.

Fuchs AF, Luschei ES (1970) Firing patterns of abducens neurons of alert monkeys in relationship to horizontal eye movement. J Neurophysiol 33:382-392.

Fuchs AF, Kaneko CR, Scudder CA (1985) Brainstem control of saccadic eye movements. Annu Rev Neurosci 8:307-337.

Fukushima K, Kaneko CR, Fuchs AF (1992) The neuronal substrate of integration in the oculomotor system. Prog Neurobiol 39:609-639.

Gioanni H, Rey J, Villalobos J, Richard D, Dalbera A (1983a) Optokinetic nystagmus in the pigeon (Columba livia). II. Role of the pretectal nucleus of the accessory optic system (AOS). Exp Brain Res 50:237-247.

Gioanni H, Villalobos J, Rey J, Dalbera A (1983b) Optokinetic nystagmus in the pigeon (Columba livia). III. Role of the nucleus ectomamillaris (nEM): interactions in the accessory optic system (AOS). Exp Brain Res 50:248-258.

Gu Y, Wang Y, Wang SR (2001) Directional modulation of visual responses of pretectal neurons by accessory optic neurons in pigeons. Neuroscience 104:153-159.

Horn AK (2005) The reticular formation. Prog Brain Res 151:127-155.

Hunt SP, Künzle H (1976) Observations on the projections and intrinsic organization of the pigeon optic tectum: an autoradiographic study based on anterograde and retrograde, axonal and dendritic flow. J Comp Neurol 170:153-172.

Kaneko CR (1996) Effect of ibotenic acid lesions of the omnipause neurons on saccadic eye movements in rhesus macaques. J Neurophysiol 75:2229-2242.

Karten HJ, Hodos W (1967) A stereotaxic atlas of the brain of the pigeon (Columba livia). Baltimore: Johns Hopkins UP.

Letelier JC, Marin G, Sentis E, Tenreiro A, Fredes F, Mpodozis J (2004) The mapping of the visual field onto the dorso-lateral tectum of the pigeon (Columba livia) and its relations with retinal specializations. J Neurosci Methods 132:161-168.

Li DP, Xiao Q, Wang SR (2007) Construction of excitatory and inhibitory receptive fields of visual isthmic neurons in the pigeon. Cereb Cortex 17:885-893.

Luksch H (2003) Cytoarchitecture of the avian optic tectum: neuronal substrate for cellular computation. Rev Neurosci 14:85-106.

McKenna OC, Wallman J (1985) Accessory optic system and pretectum of birds: Comparisons with those of other vertebrates. Brain Behav Evol 26:91-116.

McVean A, Stelling J (1986) The mechanics of pigeon eye movements-are they like other vertebrates? Behav Brain Res 19:117-121.

Moschovakis AK (1997) The neural integrators of the mammalian saccadic system. Front Biosci 2:552-577.

Moschovakis AK, Scudder CA, Highstein SM (1996) The microscopic anat- omy and physiology of the mammalian saccadic system. Prog Neurobiol 50:133-254.

Nalbach HO, Wolf-Oberhollenzer F, Kirschfeld K (1990) The pigeon's eye viewed through an ophthalmoscopic microscope: orientation of retinal landmarks and significance of eye movements. Vision Res 30:529-540.

Niu YQ, Xiao Q, Liu RF, Wu LQ, Wang SR (2006) Response characteristics of the pigeon's pretectal neurons to illusory contours and motion. J Physiol 577:805-813.

Nye PW (1969) The monocular eye movements of the pigeon. Vision Res 9:133-144.

Pettigrew JD, Wallman J, Wildsoet CF (1990) Saccadic oscillations facilitate ocular perfusion from the avian pecten. Nature 343:362-363.

Reiner A, Karten HJ (1982) Laminar distribution of the cells of origin of the descending tectofugal pathway in the pigeon (Columba livia). J Comp Neurol 204:165-187.

Robinson DA (1970) Oculomotor unit behavior in the monkey. J Neurophysiol 33:393-403.

Schiller PH (1970) The discharge characteristics of single units in the oculomotor and abducens nuclei of the unanesthetized monkey. Exp Brain Res 10:347-362.

Sparks DL (2002) The Brainstem control of saccadic eye movements. Nat Rev Neurosci 3:952-964.

Stahl JS, Simpson JI (1995) Dynamics of abducens nucleus neurons in the awake rabbit. J Neurophysiol 73:1383-1395.

Toledo CA, Hamassaki-Britto DE, Britto LR (1995) Serotonergic afferents of the pigeon accessory optic nucleus. Brain Res 705:341-344.

Tucker VA (2000) The deep fovea, sideways vision and spiral flight paths in raptors. J Exp Biol 203:3745-3754.

Wallman J, Pettigrew JD (1985) Conjugate and disjunctive saccades in two avian species with contrasting oculomotor strategies. J Neurosci 5:1418-1428.

Wallman J, Pettigrew JD, Letelier JC (1994) The oscillatory saccades of birds: motoneuronal activity and possible functions. In: Contemporary ocular motor and vestibular function: a tribute to David A. Robinson (Fuchs AF, Brandt T, Buttner V, Zee D, ed), pp 480-487. Stuttgart: Thieme.

Wang SR, Matsumoto N (1990) Postsynaptic potentials and morphology of tectal cells responding to electrical stimulation of the bullfrog nucleus isthmi. Vis Neurosci 5:479-488.

Wang SR, Wang YC, Frost BJ (1995) Magnocellular and parvocellular divisions of pigeon nucleus isthmi differentially modulate visual responses in the tectum. Exp Brain Res 104:376-384.

Wohlschläger A, Jäger R, Delius JD (1993) Head and eye movements in unrestrained pigeons (Columba livia). J Comp Psychol 107:313-319.

Wolf-Oberhollenzer F, Kirschfeld K (1994) Motion sensitivity in the nucleus of the basal optic root of the pigeon. J Neurophysiol 71:1559-1573.

Yang Y, Cao P, Yang Y, Wang SR (2008) Corollary discharge circuits for saccadic modulation of the pigeon visual system. Nat Neurosci 11:595-602.

Zhang T, Fu YX, Hu J, Wang SR (1999) Receptive field characteristics of neurons in the nucleus of the basal optic root in pigeons. Neuroscience 91:33-40. 